Connotas. Revista de crítica y teoría literarias 


\begin{tabular}{|ll|}
\hline PQ6001 & Connotas. Revista de crítica y teoría literarias / \\
Director Fortino Corral Rodríguez.-Hermosillo, Sonora: \\
unIson. Departamento de Letras y Lingüística. \\
C2011. \\
V-: $23 \mathrm{~cm}$. \\
Semianual \\
Año VII, No. $12(2011)$ \\
ISSN: 1870-6630 \\
Incluye bibliografía. \\
1. Literatura española - Historia y crítica-Publicaciones \\
periódicas. 2. Literatura hispanoamericana - Publicaciones \\
periódicas. I. Corral Rodríguez, Fortino, dir.
\end{tabular}

CONNOTAS. REVISTA DE CRÍTICA Y TEORÍA LITERARIAS. Año VII, núm. 12, enero junio 2011, es una publicación semestral editada por la Universidad de Sonora, a través de la División de Humanidades y Bellas Artes, en el Departamento de Letras y Lingüística. Blvd. Luis Encinas y Blvd. Rosales s/n, Col. Centro, C.P. 83000, Hermosillo Sonora; Tel. (662) 2592 136, (662) 2592 157, <www.uson.mx>, <http://www.connotas.uson.mx, connotas@capomo.uson.mx>. Editor responsable: Rosario Fortino Corral Rodríguez. Reservas de Derechos al Uso Exclusivo núm. 04-2006-020714184900-102. ISSN: 1870 6630; ambos otorgados por el Instituto Nacional del Derecho de Autor. Licitud de Título núm. 13434 y de Contenido núm. 11007, otorgados por la Comisión Calificadora de Publicaciones y Revistas Ilustradas de la Secretaría de Gobernación. Impresa en Impresos RM S.A. de C.V., Privada Miguel Alemán no. 17, col. San Benito, Hermosillo, Sonora, México. Tel. 2 100212, e-mail impresosrm@gmail.com. Este número se terminó de imprimir el 5 de octubre de 2011 con un tiraje de 300 ejemplares. Las opiniones expresadas por los autores no necesariamente reflejan la postura del editor de la publicación.

Se autoriza la reproducción total o parcial de los contenidos de la presente publicación, siempre y cuando se acredite adecuadamente el origen de los mismos.

Este número se publicó con apoyo del Programa Integral de Fortalecimiento Institucional

Datos de contacto para la publicación: División de Humanidades y Bellas Artes, Departamento de Letras y Lingüística; Apartado Postal 793, Col. Centro, C.P. 83000, Hermosillo, Sonora, México. Tels.: (662) 259-21-87, Tel-fax 212-55-29. Correo electrónico: connotas@capomo.uson.mx Página web: http://www.connotas.uson.mx 


\section{Connotas. Revista de crítica y teoría literarias}

Año VII / Núm. 12 / Enero-junio 2011

COMPILAdOR DE ESTE NÚMERO

César Avilés Icedo

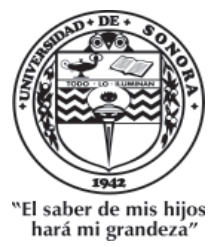

UNIVERSIDAD DE SONORA 


\section{UNIVERSIDAD DE SONORA}

RECTOR

Heriberto Grijalva Monteverde

VicerReCTORA

Arminda Guadalupe García de León Peñúñuri

Secretario General Académico

Enrique Fernando Velázquez Contreras

División de Humanidades y Bellas Artes

María Rita Plancarte Martínez

DePARTAMENTO DE LETRAS Y LINGÜÍSTICA

Martha Martínez Figueroa

COMItÉ EDITORIAL INTERNO

César Avilés Icedo

Rosa María Burrola Encinas

Fortino Corral Rodríguez

Leticia Martínez Figueroa

Jesús Abad Navarro Gálvez

Gabriel Osuna Osuna

María Rita Plancarte Martínez

DiRECTOR

Fortino Corral Rodríguez

Giuseppe Bellini

Universidad de Milán

Luis Beltrán Almería

Universidad de Zaragoza

Helena Beristáin

Universidad Nacional Autónoma de México

Raúl Bueno-Chávez

Dartmouth College

Evodio Escalante

Universidad Autónoma Metropolitana

Beatriz González-Stephan

Rice University

Aníbal González Pérez

Yale University

Aurelio González Pérez

El Colegio de México

Yvette Jiménez de Báez

El Colegio de México

Nelson Osorio Tejeda

Universidad de Santiago de Chile

\section{CONSEJO INTERNACIONAL}

Carlos Pacheco

Universidad Simón Bolivar

Rafael Olea Franco

El Colegio de México

Joan Oleza Simó

Universidad de Valencia

Julio Ortega

Brown University

Luz Aurora Pimentel

Universidad Nacional Autónoma de México

Susana Reisz

The City University of New York

José Carlos Rovira

Universidad de Alicante

Charles Tatum

The University of Arizona

Jorge Urrutia

Universidad Carlos III de Madrid

Emil Volek

Arizona State University 


\section{Índice}

\section{Artículos}

La ciudad fronteriza de Luis Humberto Crosthwaite en Estrella de la calle sexta e Instrucciones para cruzar la frontera

Martín Torres SaUchetT . . . . . . . . . . . . . . 9

Artífices y simuladores: el influjo de los medios masivos y la cultura popular en la literatura latinoamericana del siglo XX Amalia Franco Castaño . . . . . . . . . . . . . . . . . 27

“Teoría del túnel”: El pre-texto de Rayuela Margarita Díaz de León Ibarra . . . . . . . . . . . . . . 45

Metaficción hispanoamericana y crisis de la representación literaria del sujeto

Jesús Eduardo Oliva Abarca . . . . . . . . . . . . 61

Los refranes y los poemínimos: análisis de una relación intertextual

IsAbelle Pouzet . . . . . . . . . . . . . . . . . . . . . . . . 79

\section{Notas}

La ciudad como categoría estética e ideológica en Cartas de relación de Hernán Cortés y Grandeza mexicana de Bernardo de Balbuena Jesús Abad Navarro Gálvez . . . . . . . . . . . . . . . . . 99 
Hacia una hermenéutica estridentista: de la crítica romántica a la crítica de vanguardia

Alberto Rodríguez González . . . . . . . . . . . . . . . . 111

Casas de encantamiento y El espía del aire, de Ignacio Solares: la reflexión de la escritura

Alejandra Sánchez Aguilar . . . . . . . . . . . . . . . . . . 123

\section{Reseñas}

Gilberto Giménez. Estudios sobre la cultura y las identidades sociales. México: Conaculta/ITESO, 2007

Ana Lourdes Álvarez Romero . . . . . . . . . . . . . . . . . . . 135

Angélica Tornero. El mal en la narrativa de Inés Arredondo. México: Casa Juan Pablos/Universidad Autónoma del Estado de Morelos, 2008

Griselda Córdova Romero . . . . . . . . . . . . . . . . . . . . . . . 141

Guadalupe Fernández Ariza, coord. Literatura hispanoamericana del siglo XX. Historia y maravilla. España: Universidad de Málaga, 2006

Mayra Alejandra Borbón Espinoza . . . . . . . . . . . . . . 147

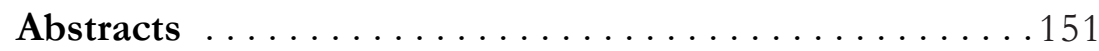

Résumés ... . . . . . . . . . . . . . . . . . . . . 157

Normas editoriales ..................... 163 
Connotas. Revista de Crítica y teoría literarias/AÑo VII, Núm. 12/2011

\title{
La ciudad fronteriza de Luis Humberto \\ Crosthwaite en Estrella de la calle sexta e Instrucciones
} para cruzar la frontera

\author{
Martín Torres SauchetT ${ }^{*}$
}

Resumen:

Uno de los aspectos que distingue a Luis Humberto Crosthwaite dentro de la literatura mexicana es el peculiar tratamiento que hace del tema de la frontera en relación particular con la ciudad de Tijuana. Más allá de sus parodias de violencia y vida nocturna desenfrenada, Crosthwaite, en Estrella de la calle sexta e Instrucciones para cruzar la frontera, nos revela dicha ciudad como una gran conciencia plural que da pie a la reconstrucción y al reencuentro de nuestras identidades y nuestra cultura, la cual no se ha dejado constreñir por los discursos puristas. Así, ambas obras podrían considerarse cartografías de un espacio que bebe tanto de la realidad inmediata como de un imaginario que la misma ciudad, a través de sus múltiples discursos, ha generado.

Palabras clave:

Tijuana, representación, identidad, cultura, espacio

Cualquier lugar del mundo, de un país o de una región en que pensemos remite ineludiblemente a determinadas características geográficas, climatológicas, políticas y culturales. Conozcamos o no esos lugares, somos capaces de imaginar atmósferas, parajes,

${ }^{*}$ Universidad Complutense de Madrid. 
asentamientos humanos y tipos de gente. Ocurre lo mismo con las ciudades, solamente que éstas poseen algo más que las define y las hace únicas. Si pensamos en lugares como París, Buenos Aires, Nueva York, Tokio, México, El Cairo o Jerusalén, encontraremos en cada uno atributos que los distinguen entre sí.

Lo que caracteriza a las ciudades fronterizas del norte de México, a diferencia del resto, es que experimentan fenómenos sociales y culturales determinados por la migración. En estos fenómenos se percibe una compleja tensión entre lo regional y lo nacional debido a que estas ciudades acogen diariamente inmigrantes que llevan a cuestas una historia y una cultura particulares, idiomas y ritos que se fusionan entre sí en el acontecer cotidiano.

En este trabajo comentaremos dos libros de Luis Humberto Crosthwaite: Estrella de la calle sexta, que consta de tres narraciones ("Sabaditos por la noche", "Todos los barcos" y "El gran pretender"), e Instrucciones para cruzar la frontera, obra que reúne nueve historias acerca de la frontera México-Estados Unidos (la de Tijuana, para ser más exactos), enmarcadas por un instructivo y un epílogo. Ambos textos son una muestra clara de la literatura bajacaliforniana y muy representativos de la literatura de la frontera. En una lectura atenta, es posible desentrañar la Tijuana de Crosthwaite, la que percibe y describe, sus calles, sus límites y sus lugares emblemáticos. Dentro de un imaginario como el de la frontera, que se resiste a ser descifrado unívocamente, el autor describe el choque de dos realidades, sus insinuaciones, sus vicisitudes y la amenaza constante del caos urbano y la violencia, donde la escritura parece ser también un ejercicio marginal. En Estrella de la calle sexta e Instrucciones para cruzar la frontera, obras que reflejan la vida cotidiana en Tijuana, encontraremos que el cuento fronterizo se caracteriza por ir más allá de sus fronteras.

En el III Encuentro de Nuevos Narradores de América Latina y España, que tuvo lugar a finales de 2003 en Bogotá, Colombia, participaron 18 escritores de 14 países, entre ellos Luis Humberto Crosthwaite, quien presentó la ponencia titulada "Al final, todos somos ciudades (apuntes para hablar de una frontera en tierras lejanas)." Inició su exposición diciendo que en su ciudad ser escritor es 
algo muy difícil de explicar, que dedicarse a la escritura en sí no tiene el mismo sentido que el de un médico que escribe el nombre de las medicinas en las recetas que da a los pacientes, o el de un ingeniero que hace anotaciones técnicas en su bitácora. Pero escribir porque sí es más complejo de lo que parece: es un ejercicio marginal. Así lo expresó: "Como ven, la vida de un escritor no es sencilla. Si lo fuera, en mi tierra podría decir que soy escritor, así, llanamente, sin que genere dudas o consternación. Y si alguien me preguntara sobre qué escribo, pues contestaría la verdad: escribo sobre mi ciudad" (148). Efectivamente, Crosthwaite escribe sobre su ciudad. En una conversación informal se le preguntó: ¿Por qué para un escritor como Luis Humberto Tijuana es un tema ineludible? A lo que respondió con ironía: "Supongo que porque no sé escribir acerca de nada más. Me encantaría escribir sobre Alejandría pero como nunca he estado ahí, pues no." Ésta es, de alguna manera, la misma idea que se le oyó en el citado encuentro: "Escribo sobre mi ciudad, porque no sé escribir sobre otra cosa" (149).

Los relatos de Luis Humberto Crosthwaite se desarrollan en Tijuana, una ciudad que tiene la connotación de finis terra, de confín y último destino, no solamente de México, sino de Latinoamérica, ya que es la última ciudad de Occidente en América Latina:

Tijuana es la ciudad más septentrional de Latinoamérica. Si ustedes se imaginan un mapa del continente americano, sabrán que es una figura extraña de pies pequeños, piernas delgadas y anchas caderas; cabezona, despeinada y con un pequeño brazo, inverosímil, que sobresale de su costado izquierdo. Ese pequeño brazo es Baja California, y Tijuana, mi ciudad, es el hombro. (Crosthwaite, "Al final" 150)

A Tijuana se han atribuido connotaciones de carácter negativo que la describen no como el hombro de una mujer, sino como "el sobaco del mundo," ciudad de desarraigo, "la Janis Joplin de las ciudades, siempre entre la pasión y el accidente" (Villoro 94). Se le ha enquistado cada vez más el estigma de terreno baldío, lugar de paso, caldo de cultivo para la explotación, paraíso para el capital 
extranjero y el infierno de los obreros en las maquiladoras. Pero para Crosthwaite, "Tijuana es una madre soltera que ha luchado por proteger a sus hijos, que ha tenido que hacer cosas vergonzosas, cosas de las cuales no se enorgullece pero que ha superado y ha salido triunfante" (150). De ella, el autor nos muestra un amplio catálogo de imágenes que superan la leyenda negra introducida por el sensacionalismo mediático.

En los textos de Luis Humberto Crosthwaite, la ciudad no es un escenario pintoresco que despierta morbo, mucho menos un mecanismo estilístico, sino "parte fundamental de la estructura narrativa, elemento dinámico y significante que se halla en estrecha relación con los demás componentes del texto" (Zubiaurre 20). La relación espacio-tiempo constituye un elemento indispensable en la organización narrativa de los textos. Esta unidad "espacio-tiempo ha de interpretarse fundamentalmente como un binomio que, dentro del contexto narrativo, y tal y como demuestra la teoría del cronotopo de Bajtin, resulta imposible de desglosar en sus dos componentes" (37). Aunque diremos algo acerca de cada uno de los términos, no quiere decir que se pretenda ignorar su inseparable interacción; al contrario, será para que notemos la estrecha relación entre los dos términos, como se puede apreciar en el primer relato de Estrella de la calle sexta, "Sabaditos por la noche," que inicia ubicándonos temporal y espacialmente: "Hey, hey, aquí nomás mirando pasar las beibis. Todos los sábados me encuentras sentadito en esta esquina" (13).

En la Tijuana de Luis Humberto Crosthwaite, conformada por un conjunto de atmósferas que confluyen en esas coordenadas espacio-temporales, tal como ocurre en "el París de Balzac y de Zola, en el Madrid de Galdós, en el Berlín de algunas de las novelas de Fontane, la gran ciudad es espacio que se basta a sí mismo y que contiene el mundo" (Zubiaurre 230). Toda proporción guardada, esta ciudad le representa a Crosthwaite el principio y el fin, el todo, lo necesario. Tijuana es el centro del universo.

"Aquí empieza la Patria," reza un letrero en la fachada del edificio de Gobierno Municipal. Es uno de los lemas que se le han querido imponer a la ciudad, como si los motes, los sobrenombres o los 
subtítulos lograran transformar a una ciudad con sólo mencionarlos. Tijuana es una ciudad de contrastes, a lo que se podría agregar una multiplicidad de calificativos que repelen la univocidad. En algún momento de su historia fue considerada lugar de destino próspero, tierra prometida, pero con el tiempo adquirió otras connotaciones, como "capital de los inmigrantes" o "la frontera más transitada del planeta." Pero también se le ha conocido como zona liberada para los juegos de azar, las cantinas y los lupanares. Así describe Crosthwaite esta faceta en la imagen de una sola calle: "Te voy a decir cómo es esta calle, cómo es mi esquina [...] es una línea recta, sucia, rodeada de cantinas, farmacias, hoteles, congales, restaurantes y muchísimos lugares que venden artesanías. No tiene una iglesia o una cruz roja que la redima y la salve del infierno cuando se muera" (Estrella 21).

La ciudad tiene una leyenda negra que se ha fraguado en el imaginario de los visitantes norteamericanos. En su doble moral, la repudian y al mismo tiempo la desean, la identifican con Babilonia, tierra de violencia y narcotráfico, de muerte, de escenario pernicioso para toda clase de crímenes, entre ellos el magnicidio de un candidato a la presidencia de la República: Luis Donaldo Colosio. Actualmente es un campo de batalla en la lucha por controlar la distribución de droga y la captación de las jugosas ganancias que se disputan los cárteles y el gobierno en sus diferentes niveles. Sin negar que estos fenómenos ocurran, esa misma Tijuana es donde tienen lugar las historias de Luis Humberto Crosthwaite, cuyas características describe Juan Villoro:

La Tijuana de sus páginas no es un parque temático para yanquis en celo, el escenario del magnicidio en Lomas Taurinas o el bastión de los medicamentos que se venden sin receta. Aunque el enclave fronterizo se convierte en protagonista absoluto de sus relatos, el narrador resiste el asedio de los temas "noticiosos" con nervios de piloto de Fórmula 1. La frontera más cruzada del mundo, principal vivero de la cultura híbrida en Mexamérica, ofrece suficientes pintoresquismos para colmar los archivos de la antropología pop. (94) 
Más allá del sensacionalismo, la esquina de Latinoamérica, donde un voyeur se sienta todos los sábados a ver pasar las "beibis," es un lugar de atmósferas muy peculiares, de espacios placenteros y opresivos, un lugar acorde con los estados anímicos de sus personajes, mentalmente complejos, de significaciones múltiples, de ángeles y demonios transitando entre la crueldad y la compasión, entre la legalidad y la transgresión, entre el deseo y la apatía. Tijuana, la esquina de Latinoamérica y, al mismo tiempo, la esquina de una calle; ambas constituyen el lugar óptimo para la epifanía o para la condenación. No hay sitio para las justificaciones ni las interpretaciones, simplemente es así, un "catálogo completo, cielo e infierno, la bondad, el carisma, el odio, la venganza, todo está en venta [...] aquí te pierdes o te salvas, aquí descubres tu verdadero yo, el último grito de la moda" (Estrella 25).

El tiempo no se entiende al margen del espacio en que transcurre o de los efectos en sus personajes, tampoco fuera de su función dentro de las historias narradas. La conjunción de ambos términos, espacio y tiempo, delinea el acontecer de los personajes, transformándolos, condicionándolos. Así como recurre al reloj para marcar horas exactas, como si se tratara de una cita o una intención de enfatizar obsesiones, Crosthwaite también echa mano del calendario para precisar fechas que le interesa tomar en cuenta o para denotar en cuánto tiempo sucedió algo. La semana, que regularmente es laboral, se vive como algo que debe finalizar lo más pronto posible para que llegue el sábado; pero lo peor llega con el domingo, preludio del lunes y la monotonía.

La noche es el momento del día en que tienen lugar situaciones importantes, es el momento privilegiado en el acontecer de los personajes. La vida irrumpe durante la noche y solamente en ese momento la sonrisa de una mujer alta y delgada como un poste puede iluminar; solamente en ese momento puede brillar la Estrella de la calle sexta, donde las "doñitas" bailan con los clientes: "Se sumergen en su danza - dice el protagonista- y uno lo hace mejor para seguirles el paso, uno-dos, uno-dos, nunca resulta, dis bato eint meid for dat chit, las ando pisando y ellas dicen 'Don guorri, mijo, its part of da yob" (Estrella 29-30). De la misma manera, es en la noche 
cuando los personajes de la marginalidad se reúnen en la esquina, confluyen en el lugar y el momento para engendrar la atmósfera en que los personajes se mueven con naturalidad.

El tiempo pasado es una pérdida que no se puede o no se quiere recuperar, que se ha roto con el presente o se ha quedado en un lugar lejano: el pasado allá y el presente aquí. Lo importante es el aquí y ahora, el lugar en el que actualmente se vive y se está: "Éste [afirma uno de los personajes] es mi paraíso. El pasado agrio lo dejo allá en el norte, del otro lado de la frontera, como se dice. Todo se queda en los Unáired, el patrón y toda su gente" (Estrella 16-17). Por otro lado, hay momentos de nostalgia porque hoy ya no es igual que antes, ya no están los que escuchaban a los Platters y eran los que daban sentido a la vida del barrio. Pero también el pasado está ligado a la música y a la identidad, remite a los orígenes, a la pregunta ¿quién soy en realidad?, y los géneros musicales están relacionados con las etapas de la vida. Como aparece en el siguiente diálogo, vemos que el rock es a la juventud lo que la música norteña a la infancia y la reconciliación con el pasado:

Mi mamá rompe el silencio.

-¿Por qué te gustan esas canciones?

$[\ldots]$

-Me gustan porque es la música de mi infancia. La que usted ponía en la casa; con ella usted cantaba, con ella usted bailaba, con ella usted me dejaba cuando salía a trabajar. [...] Cierto que la dejé de escuchar. Ya sabe cómo es uno de rebelde en la juventud. Me arropé en las cobijas del rocanrol. [...] Quise pensar que no era mía pero resulta que en cada canción, cada corrido, cada melodía con acordeón y bajo sexto, hay un pasado esencial, una parte inevitable de mi vida.

-Nuestra vida -corrige mi mamá. (Instrucciones 122-123)

Una de las imágenes más recurrentes de Crosthwaite es la espera, esa situación exasperante que mantiene a los personajes en el cautiverio de un lugar, heridos por el tiempo. En cualquier situación se espera; los personajes están marcados por ella o condena- 
dos a vivirla prolongadamente. Maniatados por el tiempo, se debe esperar el momento indicado para ejecutar a la víctima o esperar a que avance la larga fila de carros para cruzar la frontera, que entre una llamada telefónica, que llegue otra persona, que las mujeres pasen por la calle o que ocurra un suceso inesperado, pero siempre es algo que incomoda al personaje y hace notar que en ese momento ése no es el mejor lugar para estar, como aparece a continuación:

No sirvo para esperar. Odio los bancos, las filas en los supermercados; odio a los cajeros de los bancos y a los cajeros de los supermercados; odio los conciertos cuando la banda tarda en comenzar o cuando no canta las canciones que yo quiero. Cuatro horas y Lucas no llega. Podríamos repasar la historia del mundo y en ella no apestaría tanto como en esto. (Instrucciones 62)

En estos relatos, aparecen con frecuencia los lugares donde el tiempo es insoportable, eterno; en cambio, el tiempo al lado de una mujer es placentero, como un trozo de eternidad, como una necesidad: "Mejor dime palabras dulces al oído, despacito despacito, y repítelas toda la noche para que cada minuto detenga el tiempo y se atore, respirando en las entrañas de mi reloj" (Estrella 59). Tal vez no se sepa con certeza lo que se espera o para qué se espera, pero es inevitable sentir que el tiempo avanza de manera incesante, inmisericorde. Los personajes quedan en suspenso, abandonados en la desesperación y la desesperanza de lo que parece inalcanzable, como si el tiempo emprendiera la fuga hacia lugares más alentadores.

La configuración compleja de la ciudad fronteriza de Tijuana ofrece en los textos de Luis Humberto Crosthwaite una rica variedad temática en la que sobresalen de manera importante la migración, la violencia, la espera, el pasado y los diversos fenómenos fronterizos. Todo ello tiene como escenario la frontera, sus calles, la línea divisoria, su paisaje y sus sitios emblemáticos. En este caso, nos ayuda la distinción que hace José Carlos Rovira entre "paisaje" y "teatro" urbanos: 
Se entenderá por "paisaje urbano" la ciudad como objeto, al que se dirige una mirada descriptiva (o emocional, o memorial o indicadora de sentidos...). Se entenderá por "teatro urbano" el teatro con sus actores, es decir, lo que hacen los personajes que aparecen en el paisaje, sus comportamientos, sus actitudes, sus palabras, sus costumbres. (15)

Uno de los aspectos que distingue a Luis Humberto Crosthwaite dentro de la literatura mexicana es el peculiar tratamiento que hace del tema de la frontera. Esencialmente, Tijuana es fusión, movilidad, tránsito, inclusión, diversidad, pero también es límite, barrera, exclusión, frontera que se percibe físicamente en el muro metálico que implica una separación entre Estados Unidos y México, y toda Latinoamérica, tal como lo describe Crosthwaite:

La frontera es una cicatriz para todos nosotros. Es un recordatorio de nuestras propias limitaciones. Es un anuncio luminoso, permanente, que advierte una y otra vez que el mundo no está hecho de la misma materia, que existen pobreza y riqueza, y que es necesario separarlas por el bien de todos, para que una no ensucie a la otra. Esa frontera divide a nuestro continente, de manera tajante, en dos grandes partes; los de arriba y los de abajo. Eso que por leyes naturales no debería existir, es cortado violentamente por las leyes humanas. (Estrella 151)

Luis Humberto Crosthwaite relata el encuentro de dos mundos, de dos culturas. Más allá de sus parodias de violencia y vida nocturna desenfrenada, la frontera se nos revela como una gran conciencia plural que da pie a la reconstrucción y al reencuentro de nuestras identidades y nuestra enriquecida cultura, la cual no se ha dejado constreñir por los discursos puristas ni por las descalificaciones malinchistas. Sin embargo, por colindar con California, uno de los Estados más ricos de Estados Unidos, experimenta también el flagelo de la ruptura, el desprestigio y la censura. Este fenómeno lo vemos claramente en la siguiente afirmación de Bachelard: 
Dentro y fuera constituyen una dialéctica de descuartizamiento y la geometría evidente de dicha dialéctica nos ciega en cuanto la aplicamos a terrenos metafóricos. Tiene la claridad afilada de la dialéctica del sí y del no que lo decide todo. Se hace de ella, sin que nos demos cuenta, una base de imágenes que dominan todos los pensamientos de lo positivo y de lo negativo [...] Se enfrenta entonces el ser del hombre y el ser del mundo, como si se tocaran fácilmente las primitividades. Se hace pasar a la categoría de absoluto la dialéctica del aquí y del allá. Se da a esos pobres adverbios de lugar poderes de determinación ontológica mal vigilados. (250-251)

Esta tensión se hace evidente en otros binomios que expresan separación, confrontación, incluso agresión, los cuales se perciben en el ambiente y son utilizados con frecuencia para ubicarse geográfica o existencialmente, determinando la situación de las personas y sus roles respectivos en el entramado social. En este contexto, decir Norte implica decir Sur, y se sobreentiende el binomio, base o trasfondo de otros, como México-Estados Unidos, español-inglés, nosí, dentro-fuera; un sistema binario que habitualmente denota intolerancia. Obviamente, el sí, el dentro, corresponde a lo que se dice en inglés y el no, el fuera, a lo que se expresa en español, asociándolos al arquetipo del arriba y el abajo, el bien y el mal. Ante esto, Crosthwaite presenta la frontera autojustificándose:

No hay Frontera si no existe la necesidad de cruzar. Existen los cercos para mantener afuera lo que no se desea adentro, cierto; pero esas barreras no tendrían razón de ser, un sentido, si alguien no intentara cruzarlas. O sea, el límite prevalece porque hay quien desea traspasarlo. Toda Frontera existe sólo en la imaginación del que desea franquearla. Es un invento del que vive enfrentándose a ella. Un binomio perfecto. (Instrucciones 86)

El acto de cruzar la frontera guarda cierta analogía con los mitos arquetípicos de la transgresión; algo así como subir al Olimpo, fran- 
quear sus límites y penetrar furtivamente el lugar donde habitan esos seres desequilibrados y crueles, que viven en la holgura de los dioses, para robarles el fuego y luego entregarlo a los mortales en remesas mensuales. Pero para quien cruza la frontera todos los días a trabajar es una monotonía desgastante y aburrida, siempre al borde de la sospecha de los guardias de migración. Crosthwaite lo explica así:

Al enfrentar a uno de esos guardianes, debes llevar el pasaporte en la mano y la mente en blanco. Lo más apropiado es estar convencido de que ellos son seres omnipotentes, deidades, césares caprichosos capaces de arrojarte de su imperio. Lo mejor es entregarte a sus designios, por más absurdos que éstos parezcan.

Un diálogo típico podría ser así:

"¿Qué trae de México?

"Nada.

“QQué trae de México?

"Nada.

"Tiene que contestar "sî" o "no". ¿Qué trae de México? "No.

"Está bien. Puede pasar. (Instrucciones 11)

Lo cierto es que la frontera es más cruel de lo que se dice y de lo que aparenta. Es capaz de mimetizarse, tomar vida y tratar de convencer a los personajes y al lector de que la llevan dentro, que es psicológica, más que física o geográfica. Su realidad es tan compleja que se ha vuelto diestra en el arte de desmaterializarse y fingir que es imaginaria, mental, subjetiva, pero pedagógica y hasta didáctica. Así se plantea en "La silla vacía," relato en el que la Frontera toma la palabra y dice: "¿Cómo crees que se aprende? Con límites. El aprendizaje sin dolor surge de mí. Puede haber sido cruel contigo, pero no lo fui” (Instrucciones 92).

Por supuesto que con esas analogías Crosthwaite hace una crítica a las relaciones entre los dos países y a la doble moral que el muro de metal lleva implícito. Es una gran barrera vigilada extre- 
madamente por agentes de migración, cuerpos especiales equipados con la más alta tecnología, acompañados de perros entrenados, a bordo de camionetas, helicópteros, motocicletas y hasta buques de guerra; contingentes que desaparecen como por arte de magia para dar paso a la mano de obra que necesitan en esos momentos. Pero esto es extraordinario. La realidad es que la frontera está ahí y no puede sacudirse la imagen terrible que representa: es muro que divide a un continente, es la barrera entre el primer mundo y el subdesarrollo, entre la abundancia y la escasez. Y aunque se trata de algo cotidiano, de algo normal para los habitantes de la frontera, cruzarla implica una serie de complicaciones que es necesario aprender a manejar. Por eso son necesarias unas Instrucciones para cruzar la frontera: "Atravesar la línea divisoria requiere de un esfuerzo intelectual, un conocimiento de que las naciones tienen puertas que se abren y se cierran; una idea fija de que un país, cualquiera que éste sea, se guarda el derecho de admisión a sus jardines y podría echarte de ellos a la primera provocación" (9).

Los asentamientos urbanos irregulares de Tijuana, donde en la actualidad viven decenas de miles de personas, han crecido al margen de la planificación y la supervisión oficial. Desde 1950, los problemas urbanos se veían venir. Los barrios se iban erigiendo de manera informal en terrenos no urbanizados, sin servicios y de alto riesgo, como respuesta a

las fuertes corrientes migratorias, provenientes del interior del país para satisfacer la demanda de empleo que existía en California, Estados Unidos. De tales migrantes muchos no lograban cruzar la frontera, o bien eran deportados por carecer de documentos, dando como resultado el incremento de la población local y la insuficiencia habitacional. (Padilla 39)

Ésta es una historia que se ha repetido en la ciudad desde su fundación. Le llaman arquitectura emergente y se caracteriza por la escasez de recursos materiales y económicos que se emplean para satisfacer las necesidades de vivienda de las masas que arriban a Tijuana todos los días. Obviamente, no puede esperarse un resulta- 
do estético exitoso, pero sí útil, práctico y funcional. Por otra parte, resulta curioso imaginar que, estando a unos metros del país más poderoso y desarrollado del mundo - quizá ésa sea la causa- algunos barrios de Tijuana no tengan calles pavimentadas, con excepción de las avenidas principales, como los que habitan los cholos de "El gran pretender:"

Jueves de lluvia. Son las tres de la tarde y las calles están solas. Agua cayendo sobre el barrio. [...] Un arroyo atraviesa la calle. Algunos morritos salen sin que sus jefas se den cuenta, hacen barcos de papel. Los barcos se deslizan por el arroyo, entre piedras, entre lodo; y si tienes un soldadito de plástico, lo metes en el barco [...] Algunos resisten hasta el final del arroyo, hasta la avenida pavimentada; otros se caen, se ahogan, su vida por la patria. El soldadito muere.

Cuando las calles se ponen así, no hay ninguna ranfla que pueda entrar. Se resbalan, se atascan. Los cholos cansados, que apenas regresan del jale, estacionan sus ranflas en las orillas, junto a la casa del Pancho. (Estrella 102-103)

El paisaje tijuanense es abigarrado; se pasa de las barriadas más pobres a los fraccionamientos clasemedieros o a las zonas residenciales como si fuera cuestión de cruzar una calle. El centro de la ciudad es uno de los lugares que han mantenido su actividad desde su fundación; conserva parte de su atractivo turístico para jóvenes y viejos que viven al otro lado. En una sola calle de Tijuana se aglutina una horda de consumidores compulsivos y una "multitud invade el pavimento. Baila que baila. [...] Tas-tas-tas-tas. Arriba, bares con terraza. Muchachos y muchachas gritando y bailando" (Estrella 71). Se trata de la avenida Revolución, "La Revu", la más famosa de Tijuana, cuyo símbolo predomina sobre el resto de la ciudad y le da una imagen determinada que sigue atrayendo consumidores norteamericanos, para bien o para mal. Dicha imagen es la de una gran cantina, un exótico burdel, un hermoso basural por todos conocido como la avenida Revolución. En "La Revu” la noche revive esa imagen de la ciudad perversa, llena de seres anodinos que se refugian en 
los bares y los burdeles para mitigar su derrota cotidiana, su enajenación, comprando con dólares un poco de euforia o de consuelo:

pásenle, pásenle, aquí hay paso para los encantadores y los enfadosos, para los saludables y los moribundos, 'taxi taxi', sexo en los carros, en la gente y en los basureros, cualquier mirada es sensual, cualquier par de labios, de piernas, de axilas, los olores dulces, perfumados, sudorosos y podridos de alcantarillas, litros, hectolitros de cerveza, megagalones de licor, costales de droga y dólares, billetes verdes moviéndose entre dedos, deslizándose entre piernas, atrapados en pantaletas y calzoncillos... (Estrella 24)

Asimismo, por las calles transitan los automóviles - "las ranflas"como escenarios itinerantes de situaciones de dominio, de espera, de encuentros sexuales, de carta de presentación y como parte de la complejidad urbana de esta ciudad que supera todo tipo de reduccionismo, leyenda negra o propaganda noticiosa, tal como lo apunta Juan Villoro:

A Crosthwaite no le interesan los calvarios fáciles ni las superproducciones efectistas; no describe una Disneylandia XXX ni repite las denuncias del periodismo a propósito de la narcocultura o los abusos de la migra. Con detalles minuciosamente reales, construye un símbolo, una Tijuana de la mente, universal y duradera. (94)

La frontera de Tijuana es la esquina noroeste de Latinoamérica, donde en un palmo de terreno se encuentran 1) el muro de metal, 2) un faro, 3) un obelisco que marca los límites entre los dos países, 4) una plaza de toros y 5) unos excusados (Instrucciones 128). De alguna manera, se trata del mismo lugar, de la misma esquina que Crosthwaite incluye en varios de sus relatos: "Mi esquina está en la Calle Sexta, no es distinta a otras esquinas en la Calle Quinta o en la Tercera, la diferencia recae en que yo estoy sentado aquí todos los sábados mirando a las beibis" (Estrella 21). Es quizá el punto de reunión en el barrio, donde los jóvenes se juntan, porque es "la 
misma esquina donde se reunían el Saico, el Mueras, el Chemo" (82); es donde el muro fronterizo se extiende desde las afueras de Tijuana hacia los límites que permite el oeste, hasta donde se termina la tierra de Latinoamérica; pero el muro continúa y se inserta más de cien metros en el mar, sin el más mínimo pudor: "Las fronteras deberían detenerse frente al mar, quitarse el sombrero, respetar los confines que marca la naturaleza. Sin embargo, esta línea no permanece ahí, se atreve a rebasar las olas y entrar al océano con esa pedantería propia de las fronteras" (Instrucciones 124). En esa misma esquina del mundo, así como se encuentran las construcciones más disímiles, Crosthwaite narra con ironía que también tienen lugar acontecimientos extraños, como una boda entre novio norteamericano y novia mexicana, los cuales, al final de la ceremonia, no se pudieron besar; o como la ballena que decidió morir en las playas del lado mexicano y el ahogado que no decidió morir junto al muro metálico del lado mexicano; fueron las corrientes traicioneras las que lo arrojaron a ese punto:

Cuatro delegados del Ejército Zapatista de Liberación Nacional se pararon frente a la mojonera para recibir el apoyo verbal y económico de simpatizantes de ambos lados de la frontera.

[...

Era muy extraño ver a zapatistas en ese lugar: sus pasamontañas, sus paliacates rojos. Sus pies descalzos sobre la arena.

Se pararon, sin saberlo, en el mismo lugar donde

(1) había sido la boda,

(2) había muerto la ballena,

(3) se había ahogado un hombre.

Alrededor había niños que jugaban, familias que se bañaban, ambiente de fiesta en la playa. (Instrucciones 130)

Todos estos individuos que habitan y transitan la ciudad de Tijuana la recrean con su acontecer cotidiano, la reconstruyen y le dan sentido (a veces con la paradoja de su sinsentido) a los edifi- 
cios, a las calles y al mismo muro de metal que a diario les recuerda que delante de ellos tienen una frontera. Para Crosthwaite, una ciudad como Tijuana no tiene razón de ser sin quienes la habitan e interactúan con ella:

Ciudad no es la suma de sus edificios sino el paisaje urbano aunado a los pies que la recorren día con día, el resultado de sus construcciones y la experiencia de sus habitantes, no puede existir uno sin lo otro. Edificios vacíos no hacen una ciudad así como tampoco la conforma una población errante. Y la vida es un elemento primordial, la subsistencia cotidiana, la lucha de cada día. La conciencia de los múltiples ciudadanos forma una conciencia colectiva, una sola voz que se multiplica y da origen a muchas otras. ("Al final” 155)

\section{Conclusiones}

El imaginario de la ciudad que presenta Luis Humberto Crosthwaite en Estrella de la calle sexta e Instrucciones para cruzar la frontera podría considerarse un mapa que nos aproxima a una comprensión de la complejidad urbana de Tijuana. Se trata de una insinuación que no pretende dar una imagen definitiva, sino hacer conciencia de una realidad que se resiste a ser entendida unívocamente. Porque Tijuana es una ciudad de contrastes y contradicciones, de fusiones y escisiones donde se mezclan términos opuestos y se integran para enriquecerse, aunque también se dan las rupturas lamentables.

Crosthwaite se ocupa de la vida cotidiana de la ciudad fronteriza y aborda los temas centrales de su problemática, pero no cae burdamente en lo grotesco de la nota roja ni en el sensacionalismo televisivo. Al contrario, lo "mega" lo hace "mini," lo general lo hace particular, desarticula el carácter global de los acontecimientos, desmenuza los metarrelatos y cuenta en pequeños fragmentos el drama y la problemática de sus personajes: los ciudadanos fronterizos que habitan sus cuentos. 
Por encima del estigma de la leyenda negra, del mal colectivo y los escenarios pintorescos, la ciudad de Tijuana constituye el centro del universo para los personajes de Crosthwaite, su aquí y su ahora, su espacio y su tiempo, placenteros y opresivos como su complejidad anímica. Es una ciudad donde se viven, al mismo tiempo, el bien y el mal de ese paisaje abigarrado, de esa esquina de la calle sexta y de Latinoamérica, y donde la colectividad enfermiza es como una tormenta de frustraciones y fracasos; ciudad, sin embargo, donde Crosthwaite deja ver un atisbo de humanidad. De esa manera, da más importancia al individuo y lo extrae de la masa para narrar sus historias pequeñas, particulares, sin importar muchas veces que los ciudadanos no tengan nombre ni rostro ni pasado ni derechos. Al desarticular los grandes discursos, Crosthwaite escribe la historia de Tijuana con minúsculas, dando lugar al individuo que da sentido (otra vez: con la paradoja de su sinsentido) a una ciudad en la que prevalece la esperanza, a pesar de todo. Y abre una ventana desde la cual se puede descubrir que en esa ciudad también tienen lugar el amor, la felicidad y los sueños; y, ya sea por mera casualidad o por el azar caprichoso, hace coincidir a los personajes en ese tiempo y en ese espacio.

\section{Bibliografía}

Ayala, Edwin Ernesto. "El individuo, la soledad y las ciudades mentales desde la literatura urbana." Ciudad y literatura. III Encuentro de Nuevos Narradores de América Latina y España. Bogotá: Convenio Andrés Bello, 2004. 115-123.

Bachelard, Gastón. La poética del espacio. Tr. Ernestina de Champourcin. México: Fondo de Cultura Económica, 2006.

Crosthwaite, Luis Humberto. "Al final, todos somos ciudades." Ciudad y literatura. III Encuentro de Nuevos Narradores de América Latina y España. Bogotá: Convenio Andrés Bello, 2004. 147-157.

—. Estrella de la calle sexta. México: Tusquets, 2000. - Instrucciones para cruzar la frontera. México: Planeta, 2002. 
Félix Berumen, Humberto, comp. El cuento contemporáneo en Baja California. Baja California: Universidad Autónoma de Baja California/Instituto de Cultura de Baja California, 1996.

Padilla Corona, Antonio. El desarrollo urbano en la frontera. Baja California: Universidad Autónoma de Baja California, 1998.

Rovira, José Carlos. Ciudad y literatura en América Latina. Madrid: Editorial Síntesis, 2005.

Villoro, Juan. "Estrella de la calle sexta de Luis Humberto Crosthwaite." Letras Libres 24 (2000): 94-95.

Zubiaurre, María Teresa. El espacio en la novela realista. Paisajes, miniaturas, perspectivas. México: Fondo de Cultura Económica, 2000. 